\title{
DESDE EL CIELO AL INFRAMUNDO. REFLEXIONES SOBRE LAS REPRESENTACIONES CORPORALES DE INANNA Y DUMUZI A PARTIR DE LA EVIDENCIA ICONOGRÁFICA Y TEXTUAL*
}

\begin{abstract}
Desde o Céu ao Submundo. Reflexões sobre as representações corporais de Inanna e Dumuzi a partir das evidências iconográficas e textuais
\end{abstract}

\section{From Heaven to the Netherworld. Reflections on the corporal representations of Inanna and Dumuzi from the iconographic and textual evidence}

\author{
Rodrigo Cabrera** \\ Renate Marian van Dijk-Coombes ${ }^{* * *}$
}

\begin{abstract}
* Agências de fomento: Consejo Nacional de Investigaciones Científicas y Técnicas (CONICET) (Argentina)/ Stellenbosch University (South Africa).

${ }_{* * *}$ Doutorando e Licenciado em História pela Universidad de Buenos Aires. Professor da História Antiga do Oriente Próximo e seminários de línguas orientais (sumério) na Universidad de Buenos Aires. Bolsista no Consejo Nacional de Investigaciones Científicas y Técnicas (CONICET, Argentina) com local de trabalho no Instituto Multidisciplinario de Historia y Ciencias Humanas (IMHICIHU). E-mail: cabrera.pertusatti@gmail.com

*** Pesquisadora de pós-doutorado na Stellenbosch University. Doutora em Estudos Antigos (Ph.D. in Ancient Studies) pela Stellenbosch University. Mestra (M.A.) e Licenciada (B.A. Hons) em Estudos Antigos do Antigo Oriente Próximo pela University of South Africa. Bacharele (B.A. majoring) em Culturas Antigas do Oriente Próximo e Culturas Clássicas pela University of South Africa. E-mail: rmvandijk@hotmail.com
\end{abstract}




\title{
RESUMEN
}

En el presente trabajo, proponemos analizar las modalidades establecidas en la representación del cuerpo y la corporeidad de Inanna y Dumuzi, dos divinidades mesopotámicas vinculadas a la potencia vital, pero también a la muerte, a partir de la contrastación de evidencia iconográfica y textual. En nuestra investigación, nos enfocaremos en la manera en que ambas deidades son representadas en el poema $\mathrm{El}$ descenso de Inanna al Inframundo teniendo en cuenta no sólo las descripciones proporcionadas tanto en la imaginería visual como en la narrativa literaria, sino también los aportes teóricos de las disciplinas que reflexionaron sobre la noción de cuerpo en el pensamiento occidental y su aplicación a los estudios orientales.

Palabras clave: cuerpo, Mesopotamia, Inframundo

\section{RESUMO}

No presente trabalho, propomos analisar as modalidades estabelecidas na representação do corpo e a corporeidade de Inanna e Dumuzi, duas divindades mesopotâmicas ligadas ao poder vital, mas também à morte, com base no contraste de evidências iconográficas e textuais. Em nossa pesquisa, focaremos na maneira como as duas divindades são representadas no poema $A$ descida de Inanna ao Submundo, levando em conta não apenas as descrições fornecidas tanto na imagem visual quanto na narrativa literária, mas também as contribuições teóricas das disciplinas que refletiam sobre a noção de corpo no pensamento ocidental e sua aplicação aos estudos orientais.

Palavras-chave: corpo, Mesopotâmia, Submundo

\begin{abstract}
In this paper, we propose to analyze the modalities established in the representation of the body and corporeality of Inanna and Dumuzi, two Mesopotamian deities linked to the vital power, but also to death, based on the contrast of the iconographic and textual evidence. In our research, we will focus on how both deities are represented in the poem Inanna's Descent to the Netherworld, considering not only the descriptions provided by the visual imagery and the literary narrative but also the theoretical contributions of the disciplines that reflected on the notion of body in the Western thought and its application to the oriental studies.
\end{abstract}

Palavras-chave: body, Mesopotamia, Netherworld 


\section{Palabras preliminares}

La "corporeidad" como unidad de análisis ha sido abordada desde la antigüedad hasta la actualidad por la filosofía (desde los autores del mundo clásico hasta la fenomenología a fines del siglo XIX y principios del XX, que impactaron radicalmente sobre el pensamiento posmoderno) y la antropología (en espacial, la denominada "antropología simbólica"), apelando a los dualismos "alma" y "cuerpo" para privilegiar una u otra de las dos esferas en cuestión. En asiriología, la temática del cuerpo ha sido poco investigada o se han enfatizado ciertos aspectos, como el estudio de la imaginería visual - sea ésta bidimensional o tridimensional - y las figuras allí representadas, pero, en este caso, realizando meras descripciones de las fuentes empleadas.

En la presente investigación, nos enfocaremos en el estudio de la corporeidad, esto es, el cuerpo humano en cuanto cuerpo simbólico y, por lo tanto, no estático sino envuelto en la dinámica del espacio/tiempo. En palabras de Lluís Duch y Joan-Carles Mèlich, podemos observar que:

(...) el cuerpo humano es primordialmente un cuerpo simbólico, es decir, corporeidad. La corporeidad es, fundamentalmente, cinética y, por eso mismo, se significa por el hecho de que no se reduce a ser un espacio geométricamente definido, sino que se trata de un espacio atravesado por el dinamismo vital, por el deseo que «permanece siempre deseo» (Bloch) y por la energía que, incesantemente, se desprende de la espaciotemporalidad humana. Se trata, en definitiva, de un espacio temporalizado en el que, en la sucesión -a menudo monótona- de las horas y los días, se va concretando la forma de darse a conocer, de aparecer y de relacionarse que es característica del ser humano (DUCH \& MÈLICH, 2012 [2005], p. 22).

A partir de estas especificaciones teóricas, indagaremos en los fundamentos ontológicos sobre el cuerpo y las múltiples corporeidades propias de la cosmovisión mesopotámica, que rastrearemos en $E l$ descenso de Inanna al Inframundo (DII), cuya recensión corresponde 
mayoritariamente a la época paleo-babilónica (1900-1600 a.C. $)^{1}$, para cotejarlo con algunas representaciones iconográficas de los personajes centrales del mito.

El objetivo es entender cómo, tanto en el plano figurativo como documental, se (re)presentó la dualidad Inanna/Dumuzi, en cuanto opuestos complementarios, y, en paralelo, se produjeron narrativas asociadas a ambas divinidades, vinculadas a prácticas discursivas políticas y religiosas.

\section{Abordajes teóricos para pensar el “cuerpo" y la "corporeidad" en Oriente}

En la tradición occidental, las nociones de "cuerpo" y "corporeidad" aparecen plasmadas primigeniamente en la inversión nietzscheana del dualismo kantiano del homo noumenon y homo phenomenon o en la crítica de la perspectiva cartesiana expresada a través de la res cogita y la res extensa (NIETZSCHE, 1990 [18711872]; 1992 [1883-1885]). Los dualismos propios de la filosofía clásica, que perduraron hasta la modernidad, son superados en el siglo XIX por Friedrich Nietzsche. El viraje epistémico hacia lo sensible como primordial, frente a lo trascendental como subsidiario/creado, implica una crítica contra toda la filosofía precedente desde Platón, pasando por los autores medievales cristianos y arribando a la tensión entre lo nouménico y lo fenoménico en Immanuel Kant (NIETZSCHE, 1996 [1888], §43, p. 74).

La novedad de la filosofía nietzscheana radica en la inversión del dualismo platónico, donde el cuerpo se manifiesta como instrumento gnoseológico, i.e. como hilo conductor de nuestro conocimiento. Por

${ }^{1}$ El texto también se compone de fragmentos de Ur III (c. 2200-2000 a.C.), del paleobabilónico temprano (c. 2000-1900 a. C.) e, incluso, de época neo-babilónica (c. 626-539 a.C.). La primera publicación de una tablilla asociada al relato de Inanna, la BM 29628, se encuentra en Leonard William King (1902). A ella le siguieron publicaciones aisladas de tablillas que contenían partes del relato como, por ejemplo, las realizadas por Stephen Langdon (1914) y Arno Poebel (1914). Luego, sobrevinieron una serie de artículos escritos por diferentes asiriólogos, en su mayoría por Samuel Noah Kramer $(1937 ; 1939 ; 1940 ; 1942 ; 1950 a ; 1950 b ; 1951 ; 1966)$. Para los años 1970, contamos con la tesis de doctorado de William R. Sladek (1974). Más reciente es la edición y publicación electrónica del relato en ETCSL (http://etcsl.orinst.ox.ac.uk/) (BLACK et alii, 1998). 
otro lado, otra de las ideas propias de Nietzsche, que retomaremos, se vincula con los conceptos de lo "dionisíaco" y lo "apolíneo"; esto es, la presencia del carácter destructivo y caótico/pasional, asociado a la música, frente a la condición ordenada y armoniosa/racional, conectada con la arquitectura, que ya hemos reconocido en trabajos previos (cf. CABRERA, 2013).

En el ámbito de la antropología, una obra precursora sobre el cuerpo es la de Marcel Mauss, donde se alude a "técnicas corporales"2. Posteriormente, Michel Foucault (1993 [1963]; 1987 [1975]; 1995 [1976]) plantea una aproximación a los modos sobre cómo se construye la corporeidad y se disciplinan las manifestaciones del cuerpo en la modernidad.

En relación a esta última premisa, contamos con la compilación realizada por John Blacking (1977), sobre la "antropología del cuerpo", fundante en dicho campo disciplinar. En la década del '80, los trabajos en antropología del cuerpo, en cierto modo, abandonan la idea de cuerpo representacional y el enfoque semiótico - en el que el cuerpo es pensado como símbolo - y se orientan hacia la perspectiva fenomenológica (JACKSON, 1983; JACKSON, 1989; JACKSON, 1996; CSORDAS, 1993; CSORDAS, 1994; CSORDAS, 1999).

En Oriente, las investigaciones sobre el cuerpo y la corporeidad se iniciaron lentamente a fines de los ' 70 desde una perspectiva de género, haciendo foco en la relación entre el culto de las diosas y el poder político y económico de las mujeres en la antigüedad (BOULDING, 1976; ROHRLICH-LEAVITT, 1977; ROHRLICHLEAVITT, 1980; OCHSHORN, 1981). Es curioso que las indagaciones sobre el tópico del cuerpo en Oriente no sólo se alimentaron de otro campo de estudios, sino que incorporaron otra dimensión, cuya introducción resultó hasta novedosa para las disciplinas humanísticas per se: la problemática de género.

En 1986 y 1987 respectivamente, se celebraron dos congresos sobre este último tópico, donde se incluyen otras perspectivas de estudio sobre las mujeres en la antigüedad oriental, editados por Jean-

\footnotetext{
${ }^{2}$ Publicado con el título "Les techniques du corps" en el Journal de Psychologie 32 (1934) y, luego, compilado en Marcel Mauss (1971 [1936]).
} 
Marie Durand (1987) y Barbara Lesko (1989) $)^{3}$ No obstante, en el trabajo pionero de Gerda Lerner (1986) sobre género en el Próximo Oriente antiguo, se argumenta que la dominación masculina sobre las mujeres no fue "natural", sino fruto de un desarrollo histórico que comenzaría en el segundo milenio a.C. en la región.

En el Oriente antiguo, la mujer como sujeto se inserta en una red de relaciones "heterárquicas". Los vínculos "jerárquicos" forman parte de una "matriz de poder heterárquica", y, por extensión, todo poder heterárquico se construye como una modalidad de poder, presente en las interacciones entre individuos, independientemente de su grado de parentesco (SVÄRD, 2012, pp. 509-510).

Afortunadamente, en los últimos años, han aparecido diversos trabajos que incorporan otros tópicos desarrollados por la filosofía y las ciencias sociales en Occidente, permitiendo repensar la temática de la corporeidad y el género en Oriente (e.g. COUTO-FERREIRA \& GARCÍA-VENTURA, 2014; COUTO-FERREIRA, 2018). De esta manera, el anterior paradigma de estudios, en el que se insertaban muchas de las investigaciones llevadas a cabo en el Próximo Oriente antiguo se posicionaron en los llamados "estudios de la mujer", que luego dieron paso a los "estudios de género" para el área ${ }^{4}$.

Otra de las cuestiones que favoreció la incorporación progresiva de los estudios de género para pensar distintas problemáticas de la antigüedad oriental fue la complejización en el análisis de la imaginería visual, fuente por antonomasia para repensar el tópico de la corporeidad y su figuración plástica. Uno de los artículos inaugurales donde se entrecruzan la problemática de género y los estudios sobre iconografía es el de Irene Winter (1987), en el cual la autora indaga en la manera en que se representa la figura de la sacerdotisa Enheduanna en un disco homónimo, exaltando su efigie y vindicando, en simultáneo, su proyección en la arena pública. En otro artículo, Winter (1996) se enfoca en la representación monumental que realiza el rey Naram-Sîn

\footnotetext{
${ }^{3}$ En la actualidad, podemos mencionar algunos trabajos muy recientes que ponen de relieve la importancia de los estudios de género en las investigaciones llevadas a cabo en el Próximo Oriente antiguo: cf. Saana Svärd \& Agnès García-Ventura (2018) y Josué Justel \& Agnès GarcíaVentura (2018).

${ }^{4}$ A propósito de la historiografía y las perspectivas de estudio sobre la mujer en Oriente, cf. Julia Asher-Greve (2000) y Josué Justel (2011).
} 
de su propia imagen en una estela triunfal y plantea de qué manera el monarca contribuye con la cimentación de un poder público que se piensa como masculino, y cómo ocurre la intersección entre cuerpo masculino, divinidad y prácticas discursivas. En una línea argumentativa semejante, Julia Asher-Grave (1997) discute cómo se establecen categorías específicas sobre la corporeidad en sumerio y las connotaciones de las mismas en relación a las representaciones iconográficas.

Otra de las obras fundantes sobre género y su respectiva proyección visual es la de Zainab Bahrani, en la que la autora sostiene que son fundamentales "las cuestiones sobre sexo/género y subjetividad femenina en la discusión general sobre la mujer en la historia" (2001, p. 7).

En los próximos apartados, abordaremos el DII considerando las discusiones teóricas que hemos señalado hasta aquí en paralelo a las figuraciones plásticas de Inanna y Dumuzi. En este sentido, la construcción de sendos estereotipos míticos guarda una relación estrecha con las representaciones sociales de género, aunque el contenido de las narraciones mitológicas (y no así los mitos en cuanto tipologías discursivas) no guarde un vínculo de verosimilitud con respecto al contexto socio-histórico en el que se insertaba. Al respecto, Rivkah Harris sostiene que "los mitos reflejan y refractan el mundo en el que vivieron los/las autores/as, y tal vez sus propias experiencias de vida" (2000, p. 80).

\section{Las representaciones iconográficas tempranas de Inanna y Dumuzi}

La devoción por la diosa Inanna se desarrolló de forma paralela al culto a la fertilidad. Hacia fines del período Uruk Tardío, cuando aparecieron los primeros documentos administrativos (NISSEN, 1986), se reconoce el signo correspondiente a la diosa de la fecundidad, el cual también aparece en otros soportes como un motivo decorativo (fig. 1). En los textos arcaicos de Uruk, un haz de juncos con los extremos superiores doblados ( 9 f y antecedido por el determinativo divino (*) o signo an es interpretado con el valor de dinanna(ATU 208; MEA 103; 
WILCKE, 1976-1980, p. 75). Asimismo, abundan en las imágenes de sellos cilindros y sobre otros soportes ciertos tópicos que exaltaban la sexualidad femenina.
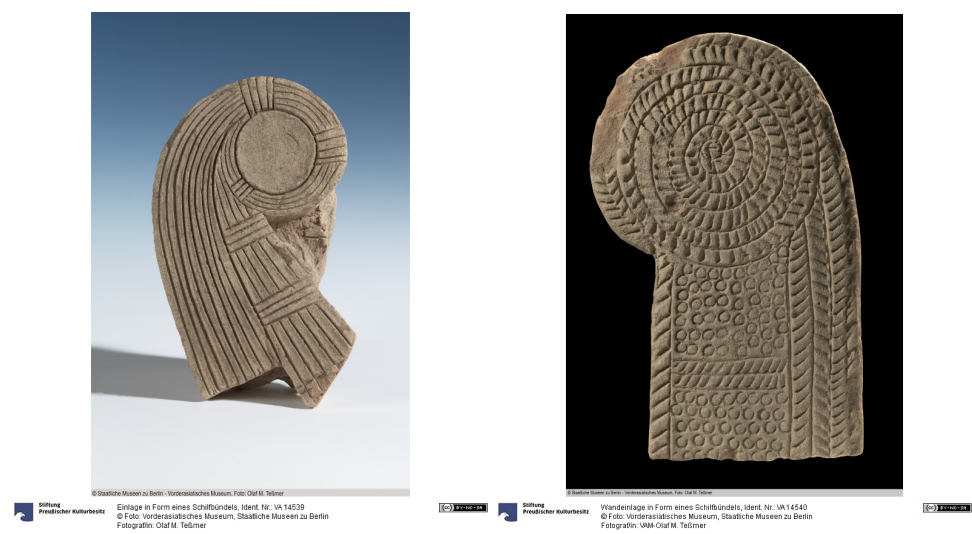

Fig. 1: El símbolo de Inanna en época Uruk ( $a$ : Va 14539 / b: VA 14539) (C) Vorderasiatisches Museum der Staatlichen Museen zu Berlin / Preußischer Kulturbesitz / VAM-Olaf M. Teßmer )

Por otra parte, en la iconografía mesopotámica, existen diversas representaciones de Inanna, pero contamos con muy pocas de su consorte Dumuzi. Una de las primeras obras, que podría mostrar a ambos dioses juntos, es el vaso de Uruk o Warka (fig. 2) de fines del cuarto milenio a.C. La pieza posee cuatro registros y el superior ostenta una figura femenina, que se identificaría con Inanna, debido a los postes con anillos detrás de ella. 

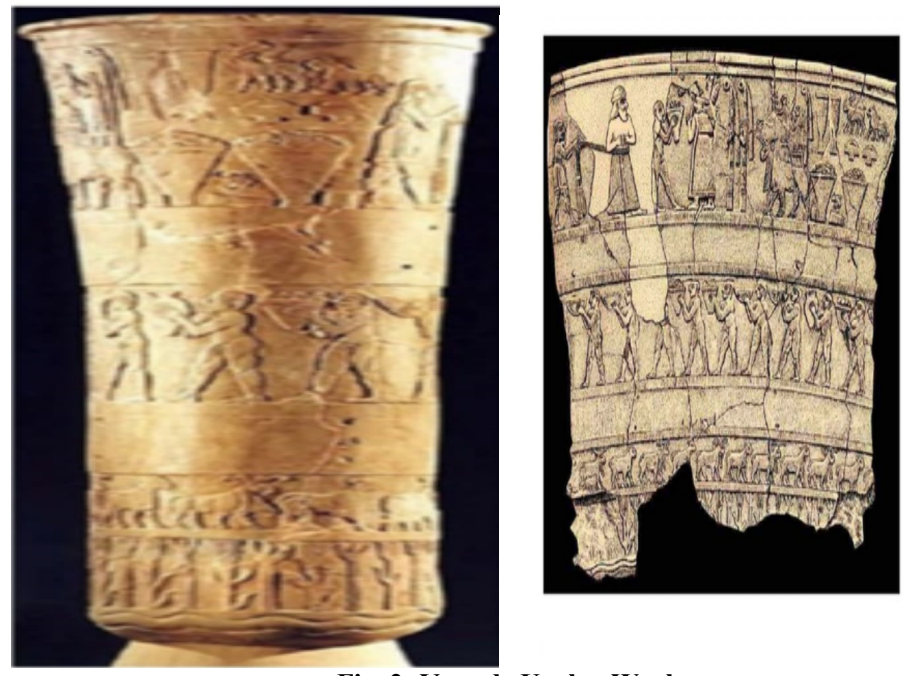

Fig. 2: Vaso de Uruk o Warka

(Recuperado de https://commons.wikimedia.org/wiki/File:Warka_Vase1.jpg)

Según Denise Schmandt-Besserat, el personaje se corresponde más bien con una sacerdotisa de la diosa (2007, pp. 43-44), aunque esta hipótesis resulta improbable, ya que a pesar de la rotura del recipiente y que la mayor parte del tocado de la figura se encuentre casi irreconocible, un cuerno, que indicaría su divinidad ${ }^{5}$, es visible justo a la derecha de la parte quebrada. Además, sobrevive una porción del registro superior, la cual permite reconstruir la escena en la que Inanna recibe a un personaje identificado como "rey-sacerdote". Se cree que dicha representación se relaciona con el rito del hieros gamos (JACOBSEN, 1976, p. 24).

A propósito, una serie de figurinas en arcilla cocida de época paleo-babilónica (Isin/Larsa) representan a una pareja copulando (fig. 3). De acuerdo con Jeremy Black y Anthony Green, éstos tendrían “algún tipo de relación con los rituales del 'matrimonio' de Dumuzi e

5 Para una discusión sobre la tiara de cuernos como un rasgo pictográfico de las divinidades, cf. Renate van Dijk (2011, pp. 130-151). 
Inanna" (1992, p. 157). Aunque esto es posible, las figuras no tienen algún significante iconográfico relacionado con la esfera divina, e.g. la tiara de cuernos, y, por consiguiente, la cópula puede también no hacer referencia a estas dos deidades.

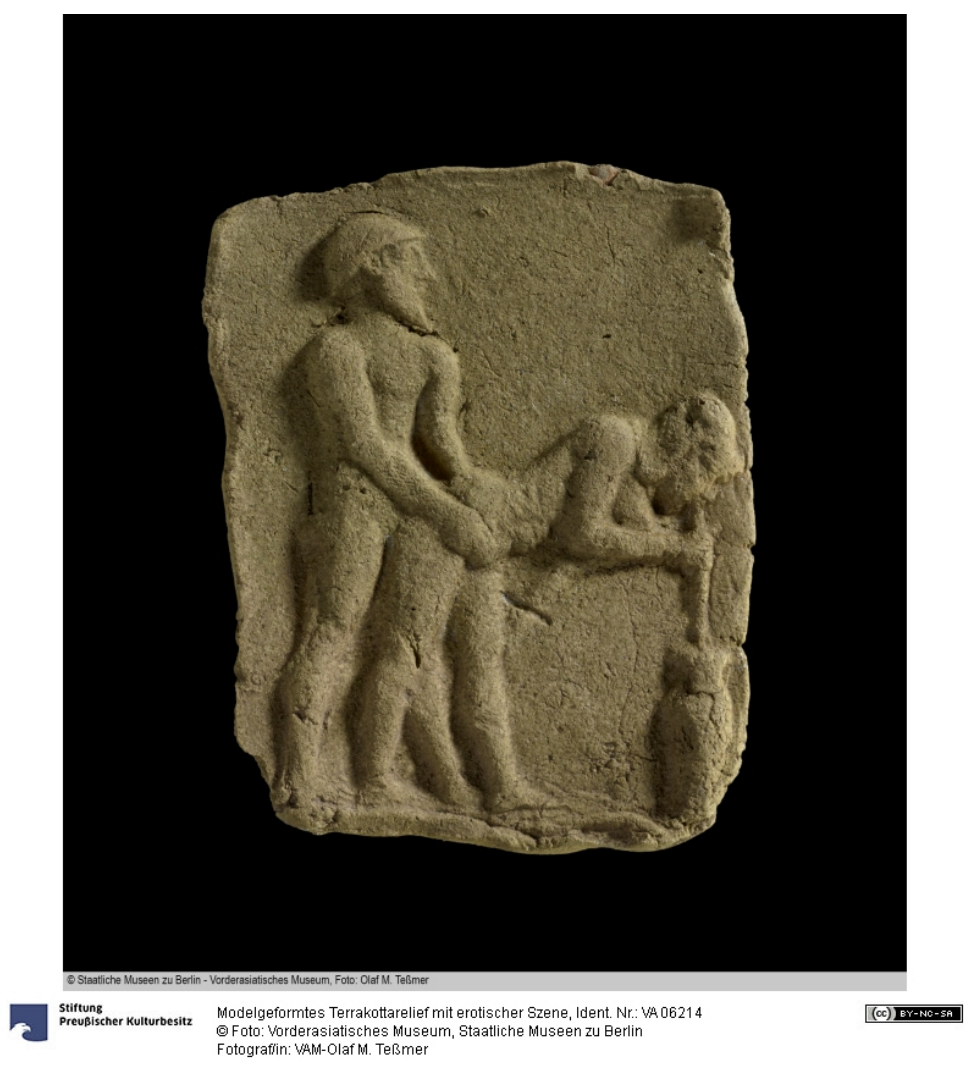

Fig. 3: Pareja copulando. La mujer está bebiendo cerveza (VA 6214) (C) Vorderasiatisches Museum der Staatlichen Museen zu Berlin / Preußischer Kulturbesitz / Olaf M. Teßmer)

Gianni Marchesi y Nicolò Marchetti sostienen que el personaje convencionalmente reconocido como el rey-sacerdote en el citado vaso 
de Uruk, en realidad, encarna a una deidad masculina, que equiparan con Ningirsu (2011, pp. 189-196). El argumento de los autores se fundamenta en la confrontación del motivo con la figura que se encuentra en un pequeño bajorrelieve del Louvre denominada "figure aux plumes" (AO 221) (fig. 4). No obstante, el tocado de plumas no es coherente con la iconografía del "rey-sacerdote".

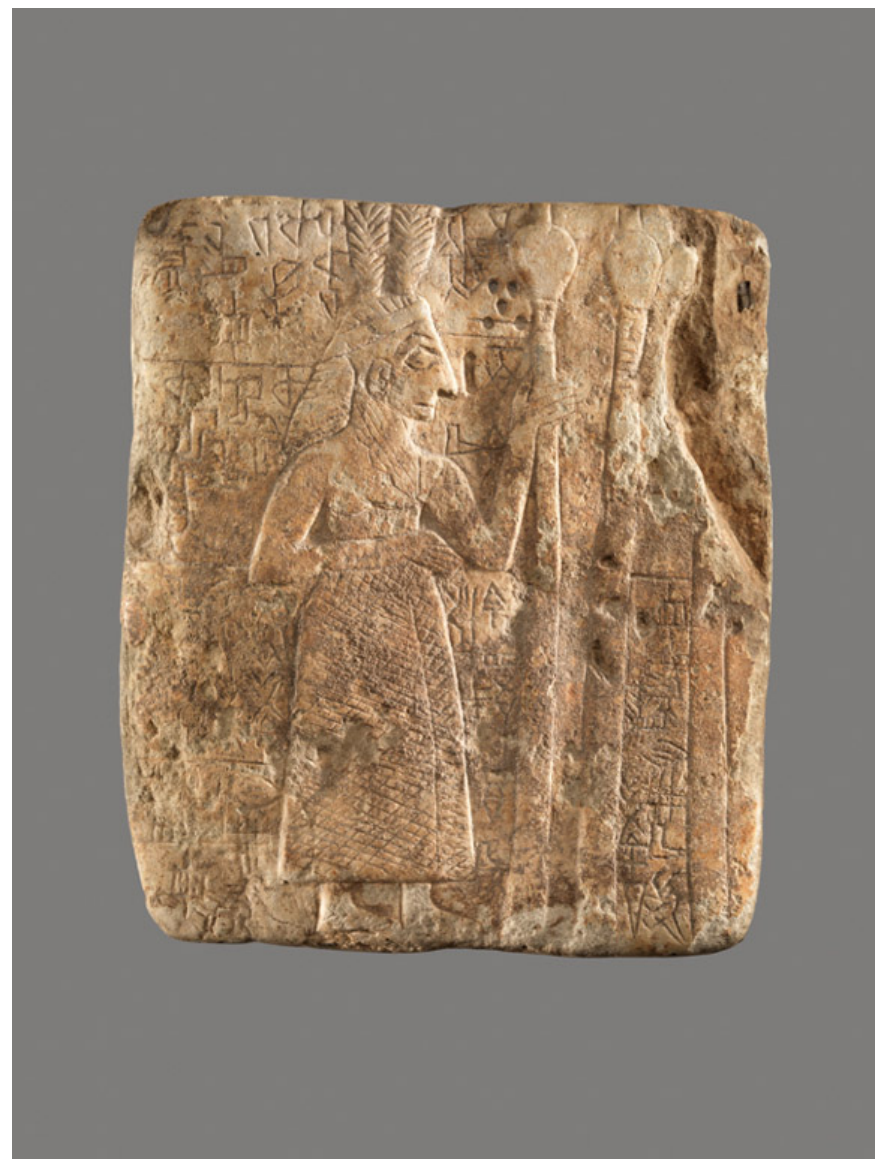

Fig. 4: Figure aux plumes (AO 221)

(C) Musée du Louvre, dist. RMN-GP / Philippe Fuzeau) 
Por otra parte, Donald Hansen sugiere que la figura del reysacerdote pertenece a Dumuzi (1998, p. 49), mientras que Thorkild Jacobsen postula que la representación corresponde a Amaušumgalanna, i.e. el esposo de Inanna (1976, p. 24). Esta postura no es incongruente con la anterior, dado que Dumuzi, desde el Protodinástico, poseía como uno de sus epítetos el de Amaušumgalanna (LEICK, 1998, p. 31). En los sellos cilindros del período de Uruk, se muestra al rey-sacerdote llevando una espiga de cebada. El pictograma correspondiente a la espiga de cebada, pero convertido en cuneiforme y con el determinativo divino delante se transforma en el signo para Dumuzi (DOUGLAS VAN BUREN, 1945, p. 13). En suma, si la figura del rey-sacerdote representa a un dios, la misma debería ser la de Dumuzi.

\section{Inanna y el cuerpo dionisíaco de la deidad: la "Reina de la Noche"}

En el DII, la imagen del cuerpo de la diosa se relaciona con una serie de prácticas rituales, que posibilitan el ingreso de Inanna a la "Tierra sin Retorno" o Kurnugia. Las descripciones del DII permiten reconocer la intertextualidad del relato y, de este modo, delimitar el contexto de escritura del mismo. Diversos estudiosos considerar al DII como una obra polifónica, que remite a otras narraciones como El sueño de Dumuzi o Dumuzi y Geštinanna (SLADEK, 1974; KATZ, 1996, p. 93, CABRERA, 2015). En cierta manera, la integración del DII en un sustrato mítico mayor serviría para remarcar los aspectos dionisíacos/tremendos de Inanna y contraponerlos a sus caracteres apolíneos/fascinantes, que aparecen mencionados al comienzo del relato.

Asimismo, en el DII, así como en otras fuentes, Inanna está asociada a ciertas expresiones sensibles, que indicarían su antropomorfización (SLOBODZIANEK, 2010, pp. 28-29). En este sentido, la humanización de Inanna explicitaría el nexo existente en la construcción de la corporeidad de la deidad con la realeza como institución de orden y poder, y, por tanto, con el cuerpo monárquico, al que estaría vindicando de algún modo, como en Inanna y Ebih. En la 
narración, se exaltarían los rasgos más belicosos de la deidad o su "terror reverencial", denominado ni $_{2}$ (sumerio) o puluhtu (acadio) en la cosmovisión mesopotámica ${ }^{6}$.

La descripción de la diosa al comienzo del DII ofrece una imagen de orden y perfección. Antes de descender a la Tierra sin retorno, Inanna se jacta de manipular las "fuerzas divinas" o me y se prepara ritualmente con diversos atavíos ceremoniales. Curiosamente, tanto las fuerzas divinas como las vestiduras de la diosa suman en total siete, en coincidencia con los siete portales del Inframundo, que debe atravesar una vez que se desprende de las mismas.

14. me imin-bi za $a_{3}$ mu-ni-in-kešda

15. me mu-un-ur 4 -ur 4 šu-ni-še 3 mu-un-la 2

16. me šar ${ }_{2}$ giri $_{3}$ gub-ba i-im-ĝen

17. ${ }^{\text {tug2 } 2 \text {-šu-gur-ra men edin-na saĝ-ĝa }}{ }_{2}$-na mu-un-ĝal ${ }_{2}$

18. hi-li saĝ-ki-na šu ba-ni-in-ti

19. ${ }^{\text {na }}{ }^{\text {za-gin }} 3$ di $_{4}-\mathrm{di}_{4}-\mathrm{la}_{2} \mathrm{gu}_{2}$-na ba-an-la 2

20. ${ }^{\text {na4}}$-nunuz tab-ba gaba-na ba-ni-in-si

21. ${ }^{\text {tug } 2}$ pala $_{3}{ }^{\text {tug } 2}$ pala $_{3}-a^{7}$ bar-ra-na ba-an-dul

22. šimbi lu $\mathrm{lu}_{2} \mathrm{he}_{2}$-em-du he $\mathrm{h}_{2}$-em-du igi-na ba-ni-in-ĝar

23. tu-di-da lu $\mathrm{lu}_{2} \mathrm{ga}_{2}-\mathrm{nu} \mathrm{ga}_{2}$-nu gaba-na ba-an- gid $_{2}$

24. har guškin šu-na ba-an-du

25. gi-diš-ninda eš $\check{2}_{2}$ gana 2 za-gin 3 šu ba-ni-in-du

26. IInanna kur-šse 3 i-im-ĝen

14. Las siete "fuerzas divinas"8 ella tomó.

15. Recogió las "fuerzas divinas", entre sus manos las transportó.

16. La totalidad de las "fuerzas divinas" tuvo en su poder".

\footnotetext{
${ }^{6}$ El término $\mathrm{n}_{2} /$ /puluhtu se traduce con el sentido de "miedo" (ePSD N; CAD P: 505).

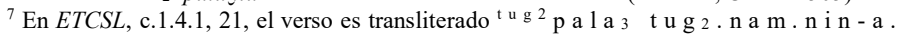
El vocablo pala 3 se puede transcribir como NAM.N N, es decir, "dignidad de nin (sumo sacerdotisa)". En efecto, ${ }^{\mathrm{t} u \mathrm{~g}} 2$ p a 1 a 3 es exactamente igual a t u g $2 . \mathrm{n} \mathrm{a} \mathrm{m} \mathrm{.} \mathrm{n} \mathrm{i} \mathrm{n} \mathrm{.} \mathrm{El} \mathrm{determinativo}$ para vestidos, ${ }^{\text {t u g } 2}$, especifica que es un "traje de sumo sacerdotisa".

8 En sumerio, el vocablo $\mathrm{m}$ e significa "ser", "propiedades divinas que permiten la actividad cósmica"; "oficio"; "orden (cúltico)"; "rigidez"; "silencio"; "limpiar"; "deseo" (ePSD M). El concepto de $m$ e equivale al acadio parșu. En el campo de la asiriología, ha sido abordado por diferentes autores, e.g. Karl Oberhuber (1963), Gertrud Farber-Flügge (1973), Yvonne Rosengarten (1977), Annette Zgoll (1997) y Vladimir Emelianov (2004, 2009, 2010).
} 
17. El turbante, la corona de la estepa, colocó sobre su cabeza.

18. Ella se colocó una peluca sobre la frente ${ }^{10}$.

19. Una gargantilla de piedras de lapislázuli muy pequeñas se colgó en el cuello ${ }^{11}$.

20. Dos perlas ovaladas se insertó en el pecho.

21. Con los trajes de sumo sacerdotisa ella cubrió su cuerpo.

22. Con el cosmético "que venga el hombre, que venga" ella se pintó los ojos.

23. El pectoral "ven hombre, ven" lo extendió sobre su pecho.

24. Ella se puso un brazalete de oro en la mano.

25. La vara de una ninda y la cuerda de gana hechas de lapislázuli llevó entre sus manos

26. Inanna fue hacia el Inframundo.

\section{Tablillas Ni 368 + CBS 9800; CBS 1393; CBS 12368+12702+12752; Ni 2279 \\ (ETCSL c.1.4.1: 14-26)}

La manipulación ontológica de las fuerzas divinas y los ropajes se relaciona con la preparación y posterior periplo de Inanna hacia el Inframundo ${ }^{12}$. En este sentido, las vestiduras de la diosa, en tanto atavíos ceremoniales, son necesarias para realiza el rito de paso al mundo de los muertos y, por lo tanto, en el plano metafórico, la

\footnotetext{
${ }^{9}$ En sentido literal, $\mathrm{g}$ i $\mathrm{ri}_{3}-\mathrm{g} \mathrm{u} \mathrm{b}$ denota algo así como "poner el pie sobre algo", pero significa "pisar", "entrar", "salir" (ePSD Ĝ). Aquí podemos traducirlo como "puso el pie encima de la totalidad de las fuerzas divinas".

${ }^{10}$ El vocablo hi $\mathrm{i}-1 \mathrm{i}$ es polisémico y se vincula con la palabra hili $\mathrm{b}_{2}$. Ambas significan "atractivo sexual", "(ser) exuberante", "tener placer", así como también "peluca ritual" (ePSD H). En ETCSL, el verso es traducido "ella toma una peluca para su frente" (t.1.4.1, 14-19) y, en una traducción temprana, "mechones de pelo ella se fijó a la frente" (KRAMER, 1951, p. 2). El verbo $\breve{\mathrm{s}} \mathrm{u}-\mathrm{t} \mathrm{i}$ tiene por significado "aceptar", aunque adopta las siguientes acepciones en acadio: lequ, es decir, "tomar (el control)", y mahäru, "enfrentar", "confrontar", "oponerse", "recibir" (ePSD Š). El uso de trajes y pelucas para vestir estatuas con fines rituales era algo habitual en los templos mesopotámicos.

${ }^{11}$ En el DII, la "gargantilla de piedras de lapislázuli" está vinculada con el poder divino, que es justo y no se considera arbitrario, a pesar de aparecer con un carácter coactivo. En La exaltación de Inanna, conocida en sumerio por su íncipit como $n$ i n $m$ e $\breve{s}$ a $\mathrm{r}_{2}-\mathrm{r}$ a, se describen algunos rasgos coléricos de la deidad, que se relacionarían con el orden y la justicia, como el término š a 3 $\mathrm{i}_{3}-\mathrm{h}$ u $1_{2}$, que también aparece en diversas inscripciones de Šulgi (SLOBODZIANEK, 2010, p. 30).

${ }_{12}$ E.g. Enki y el orden del mundo e Inanna y Enki. En ambos registros textuales, se describe a las fuerzas divinas como potencias vivificadoras y dinamizadoras del cosmos.
} 
descripción del cuerpo engalanado de la divinidad expresaría la noción de viaje y pasaje al Inframundo (VERDERAME, 2009, pp. 68-70). En otros relatos, como en Dumuzi y Geštinanna, también está presente esta conexión, así como la idea de intertextualidad entre sendas narraciones.

7.tug -ba $_{13}$ kug tug ${ }_{2}$ pala $_{3}$-a tug 2 nam-nin-zu nam-ba-mu-mu4-un kur$\mathrm{se}_{3} \mathrm{ed}_{3}-\mathrm{de}_{3}$

8. men kug me-te ka silim-ma saĝ-zu-a um-ta-ĝa $a_{2}-a r$ kur-še ${ }_{3}$ ed $_{3}-\mathrm{de}_{3}$

9. ĝi-li-a igi-zu la-ba-ni-in-du $\mathrm{kur}^{-} \mathrm{Se}_{3} \mathrm{ed}_{3}-\mathrm{de}_{3}$

7. No te pongas tu sagrado traje $b a$, no te pongas los trajes de sumo sacerdotisa, desciende hacia el Inframundo.

8. Quítate el sagrado tocado, el espléndido ornamento de tu cabeza, desciende al Inframundo.

9. No realces tu apariencia con una peluca, desciende al Inframundo.

\section{Dumuzi y Geštinanna \\ (ETCSL c.1.4.1.1: 7-9)}

La descripción del cuerpo de Inanna en el DII y en el mito anterior se relaciona con la idea de perfección y ordenamiento en el plano cósmico, ya que aparece vinculada a la noción de fuerza divina y, por extensión, de justicia, normatividad y magnificencia. En este sentido, el cuerpo de la diosa muestra un aspecto apolíneo en contraposición a los rasgos dionisíacos, que asumirá al final del relato cuando condene a Dumuzi y exhiba una cara totalmente nefasta. No obstante, cuando atraviesa los siete portales y se encuentra desnuda frente a Ereškigal, se presenta a través del arquetipo de "diosa doliente" y sucumbe ante los Anunna.

164. gam-gam-ma-ni tug 2 zil-zil-la-ni-ta $\operatorname{lu}_{2}$ ma-an-de 6

165. nin $_{9}$-a-ni giš gu-za-ni-ta im-ma-da-an-zig 3

166. e-ne ĝ̀ǐs gu-za-ni-ta dur 2 im-mi-in-ĝar

167. ${ }^{\mathrm{d}} \mathrm{A}-n u n-n a$ di-kud imin-bi igi-ni-še 3 di mu-un-da-kus-ru-ne

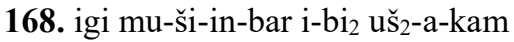

169. inim i-ne-ne inim-lipiš-gig-ga-am 3

170. $g_{3}$ i-ne-de ${ }_{2} g_{3}$ nam-tag-tag-ga-am 3

171. munus tur 5 -ra uzu-nig $\hat{g}_{2}-\mathrm{sag}_{3}$-ga-še $\mathrm{e}_{3}$ ba-an-kur 9 
172. uzu-nig $\hat{g}_{2}-\mathrm{sag}_{3}$-ga ${ }^{\text {gìis } k a k-t a ~} \mathrm{lu}_{2}$ ba-da-an-la 2

164. Una vez que se encuentra encorvada [y] se le quitan los ropajes, se la llevan ${ }^{13}$.

165. Su hermana ${ }^{14}$ se levantó de su trono.

166. Ella se sentó en su trono.

167. Los Anunna, los siete jueces, pronunciaron una sentencia ante ella.

168. La miraron [con] la "mirada de la muerte".

169. Le hablaron [con] la "palabra de la ira".

170. Le lanzaron el "grito de la culpa".

171. La mujer, enferma, fue convertida en un cadáver.

172. El cadáver fue colgado de un clavo.

\section{Tablilla CBS 15212 \\ (ETCSL c.1.4.1: 164-172)}

Diversos estudiosos han planteado que la desnudez de Inanna es sinónimo de expiración. Asimismo, otros autores sostienen que el acceso de la diosa al Inframundo sin sus ropajes ni sus poderes divinos sería una estrategia persuasiva elucubrada por Ereškigal y no un requerimiento para entrar al Inframundo demandado a todos los forasteros (KATZ, 1995, pp. 221-223). Sin embargo, la necesidad de despojar a Inanna de sus atributos está asociada al deseo de destruir el cuerpo sagrado y magnificente de la diosa, eliminar su potencialidad divina, su imagen aterradora, sojuzgarla y aplacar el miedo/puluhtu que generaba.

En otras fuentes documentales e iconográficas, estos aspectos temibles de la diosa son exaltados y creemos, por consiguiente, que debían ser neutralizados o sometidos. Por ejemplo, una figura, a menudo identificada con Inanna y conocida como "Reina de la noche" o relieve Burney (ANE 2003-718.1) (fig. 5), exhibiría ciertos rasgos propios de la deidad en el DII.

13 En ETCSL t.1.4.1. 164-172, el verso es traducido: "Después de que ella se habia agachado y se habia quitado la ropa, se la llevaron".

${ }^{14}$ Es decir, la hermana de Inanna, Ereškigal. 


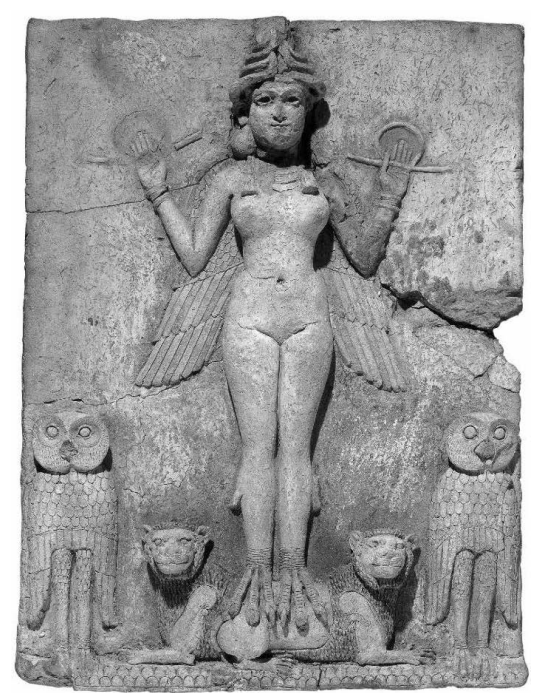

Fig. 5: Relieve Burney o "Reina de la Noche" (ANE 2003-718.1/ AN33323001) (C) The Trustees of the British Museum)

La representación muestra a una diosa desnuda modelada en alto relieve con alas colgando de sus hombros. La misma lleva un casco con cuernos, que marca su divinidad, un collar y ostenta un anillo y una vara en cada mano. Sus pies tienen forma de garras de ave de rapiña, mientras se alza sobre las espaldas de dos leones y está flanqueada por dos lechuzas. Dichos animales están ubicados en un patrón de escala que indicaría la presencia de montañas.

Además, existen placas moldeadas en terracota (e.g. AO 6501) (fig. 6) e impresiones de sellos cilindros (WOLKENSTEIN \& KRAMER, 1983, p. 51) con caracteres semejantes a los del relieve Burney. Sin embargo, la deidad del relieve es la única figura en la imaginería mesopotámica realizada sobre dos leones, portando el símbolo del anillo y la vara. Otras representaciones efectuadas en placas de terracota también parecen tener pies humanos, en vez de garras de ave. Las similitudes sugieren que, a pesar de las diferencias, las figuras que encontramos en la estatuaria, en las 
improntas de sellos cilindros y en el relieve Burney representan a la misma diosa, conocida popularmente como "Reina de la Noche" (ALBENDA, 2005).

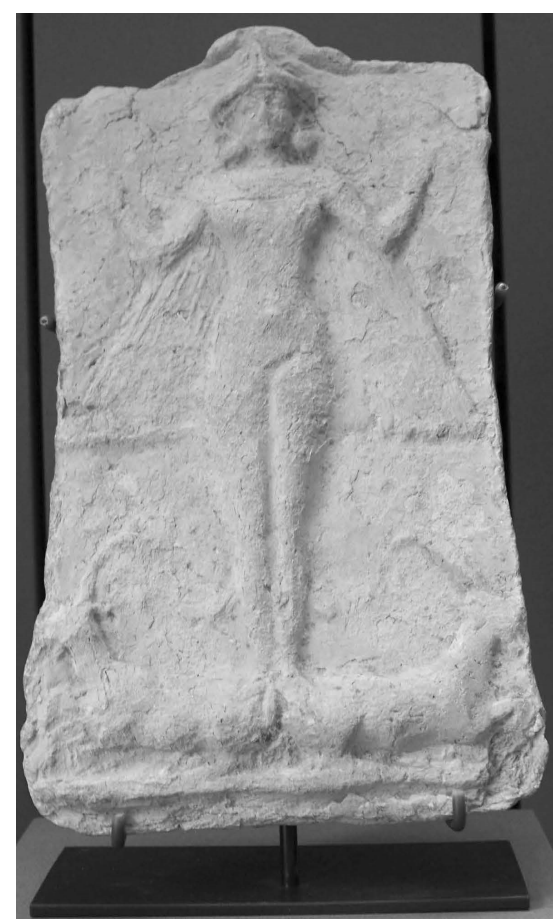

Fig. 6: Placa en terracota de Inanna (AO 6501)

(C) Photo RMN / Franck Raux)

En 1937, un año después de que el relieve fuera publicado por primera vez en el Illustrated London News, Emil Gottlieb Kraeling consideró que la deidad representada no era Inanna, sino Lilitu (la Lilith hebrea) (1937, p. 18). Algunos autores siguen apoyando dicha hipótesis, aunque la misma ha sido abandonada ampliamente, ya que Kraeling identificó a la Reina de la Noche con Lilitu, debido a una traducción errónea de la Épica de Gilgameš. 
Para Thorkild Jacobsen, la figura del relieve Burney muestra uno de los aspectos de Inanna en calidad de diosa de las rameras y, por ende, la escultura sería exhibida originalmente en un burdel (1986, pp. 1-11). A favor de dicho posicionamiento, se encuentra el león como animal prototípico de Inanna -en calidad de ekdu, i.e. "fiero"- y la vara y el anillo, las cuales Inanna en el DII manipula antes de ingresar al Inframundo. Según Jacobsen, el collar de la "Reina de la Noche" le otorga el estatus de prostituta a la portadora y las montañas debajo de los leones simbolizan el hogar original de Inanna al este de Mesopotamia. Del mismo modo, Diane Wolkenstein y Samuel Noah Kramer sugieren que la figura personifica "el aspecto ctónico de Inanna/Ishtar [que] deriva de su asociación a las criaturas demoníacas y con frecuencia a las aves y los dioses que habitan el mundo subterráneo" (1983, p. 189). Si la Reina de la Noche es Inanna, la inexistencia de ropa puede ser indicativa de la desnudez de la deidad cuando desciende al Inframundo.

Dado que la premisa de que la Reina de la Noche reflejaría algún aspecto de Inanna es tan perspicaz, un vaso hallado en Larsa y conservado en el Louvre (AO 17000) (fig. 7), el cual tiene cuatro placas en miniatura que representan a la diosa, así como una imagen inscrita y pintada de la misma, se conoce actualmente como el "vaso de Ištar" (DEMANGE et alii, 1995, p. 59). 


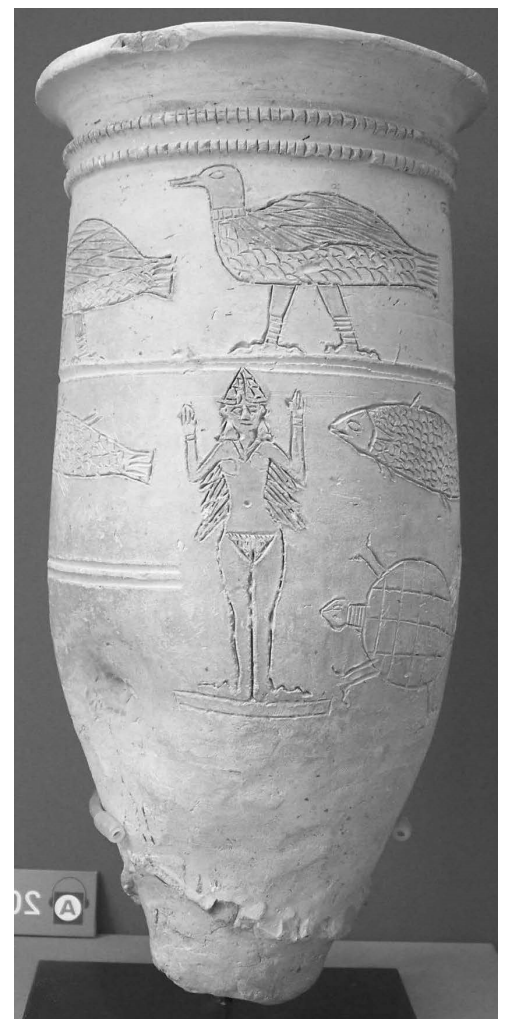

Fig. 7: Vaso de Ištar (AO 17000)

(@ R.M.N./J. Galland)

Sin embargo, aunque Thorkild Jacobsen dé razones para identificar a la Reina de la Noche con Inanna, también la misma podría ser Ereškigal, la divinidad de los muertos y hermana de la anterior. Las alas hacia abajo de la divinidad, así como las lechuzas y el fondo negro del relieve, podrían dar cuenta de la conexión de la diosa con el Inframundo. Además, las montañas, que Jacobsen relaciona con el hogar primigenio de Inanna, podrían ser también una proyección del mundo de los muertos, dado que la palabra sumeria más común para definir al Inframundo - al menos en la literatura- se escribe con el signo kur, que también significa "montaña” (KATZ, 2003, p. 63 у passim). 
Por otra parte, las divinidades masculinas y femeninas son representadas empuñando una vara y un anillo entre sus manos, cuyos objetos son entregados a un rey en actitud orante - como en el caso de la famosa estela en la parte superior del Código de Hammurabi -, simbolizando el poder y la justicia para ejercer un buen gobierno (BLACK \& GREEN, 1992, p. 156). No obstante, la Reina de la Noche posee una vara y un anillo en cada una de sus manos. La vara y el anillo propios de Inanna podrían habérsele arrebatado en su visita a su hermana en la Kurnugia, y el relieve Burney, de este modo, personificaría a Ereškigal, sosteniendo su vara y su anillo más los pertenecientes a la intrusa (ARUZ, BENZEL \& EVANS, 2008, p. 22). Dominique Collon se inclina por esta idea, pero admite que no existe un nexo directo entre la figura del relieve Burney y Ereškigal, dado que la iconografía vinculada a la deidad del Inframundo no es del todo conocida (2005a, pp. 43-45).

\section{Dumuzi y el cuerpo apolíneo de la divinidad: el "dios muerto en el sarcófago"}

La última parte del $D I I$ es indicativa de otros atributos propios de la corporeidad de Inanna y de su consorte Dumuzi. En primer término, son peculiares las conexiones entre esta sección del mito y el relato conocido como Dumuzi y Geštinanna, del que el DII habría tomado algunas estructuras. Asimismo, el nexo entre ambas narraciones contribuyó a transformar a Dumuzi en víctima de Inanna (KATZ, 1996, pp. 93-103) y, de este modo, lo tremendo/dionisíaco de la diosa predominaría sobre lo benéfico/apolíneo del pastor. El ascenso de Inanna la convierte de víctima en victimaria y a su paredro en el depositario de su terror o puluhtu.

353. sipad-de gi-gid $_{2}$ gi-di-da igi-ni šu /nul-mu-un-tag-ge-ne

354. igi mu-un-ši-in-bar igi-ušs-a-ka

355. inim i-ne-ne inim lipiš-gig-ga

356. $\mathrm{gu}_{3}$ i-ne-de $\mathrm{gu}_{3}$ nam-tag-tag-ga

357. en $_{3}$-še tum $_{3}$-mu-an-ze 2 -en

358. kug ${ }^{d}$ Inanna-ke ${ }_{4} \mathrm{su}_{8}-\mathrm{ba}^{\mathrm{d}}$ Dumu-zid-da šu-ne-ne-a in-na-šum 2 
353. El pastor ya no tocó ni su oboe doble, ni su flauta en presencia de él.

354. Ella lo miró (Inanna a Dumuzi) [con] "la mirada de la muerte".

355. Ella le habló (Inanna a Dumuzi) [con] la "palabra de la cólera".

356. Ella le gritó (Inanna a Dumuzi) [con] el "grito de la culpa":

357. “¿Hasta cuándo? ¡Llévenselo!”

358. La pura Inanna entregó al pastor Dumuzi en sus manos (es decir, a los demonios).

\section{Tablilla YBC 4621 obv. y rev (ETCSL c.1.4.1: 353-358)}

La construcción de Inanna como destructiva/entregadora se manifiesta en el momento en que la deidad condena a Dumuzi del mismo modo que los Anunna hicieron con ella, a través de diferentes recursos discursivos, como la frase de la línea 354: Ella lo miró (Inanna a Dumuzi) [con] "la mirada de la muerte" / igi mu-un-ši-in-bar igi-ušsa-ka. La "mirada de la muerte", lanzada contra Dumuzi, transforma a Inanna en una deidad del Inframundo, en una divinidad predadora, y asemejan la secuencia narrativa a otros ciclos míticos del Mediterráneo. De este modo, el joven pastor se torna un dios doliente e Inanna paradójicamente lamenta su pérdida. En el mito, se opone la imagen dionisíaca de Inanna a la apolínea propia de Dumuzi y se exaltan los caracteres liminales, opuestos y complementarios, masculinos/femeninos, uránicos/infernales de la deidad del amor y la guerra (HARRIS, 1991).

Los motivos pictóricos, que podrían asociarse con escenas del ingreso de Dumuzi al Inframundo, se encontrarían en diversas impresiones de sellos cilindros. Uno de ellos, el A 17004, muestra una figura arrodillada atacada por demonios con cabezas de leones y con pies de aves y por un personaje masculino con múltiples mazas y una espada. Si estos demonios se identifican con los galla (WOLKENSTEIN \& KRAMER, 1983, 191), este sello puede ser un indicio del ataque de estas criaturas contra Dumuzi, dado que lo arrastran al mundo de los muertos.

Existen otras representaciones sobre sellos cilindros, que describen secuencias semejantes, e.g. uno de origen paleo-acadio (AO 2485) (fig. 8), identificado como "la victoria de Nergal", donde aparece 
una diosa flanqueada por dos montañas, que probablemente representen al Inframundo. En la montaña a la derecha de la diosa, una deidad masculina, identificada como Nergal, sostiene a un hombre-toro por la cola, mientras que, en la montaña de la izquierda, una divinidad, que porta un flagelo, toma el cuerno de otro dios. La figura femenina tiene rayos, que se extienden desde sus hombros, y carga un anillo. Diane Wolkenstein y Samuel Noah Kramer postulan que el anillo puede ser el mismo que Inanna se quita cuando accede a la quinta puerta del Inframundo, $\mathrm{y}$, por lo tanto, la representación corresponda a la divinidad (1983, p. 190). Si en el objeto se escenifica el DII, es posible que la deidad atrapada en la montaña de la izquierda personifique a Dumuzi.

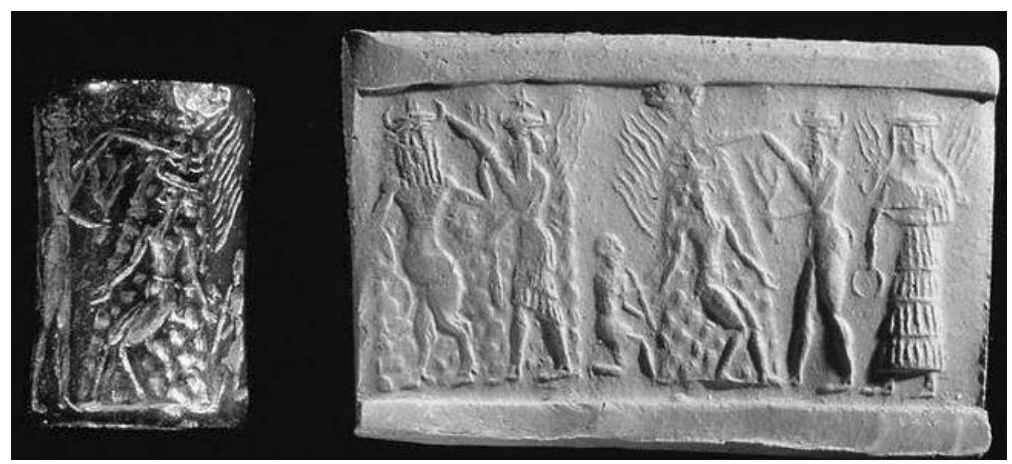

Fig. 8: La victoria de Nergal (AO 2485)

(C) Musée du Louvre/C. Larrieu)

Otro sello del Protodinástico (BM 123279) (fig. 8) ostenta un dios montado en una bestia, un hombre desnudo atrapado en una especie de red, una deidad, cuyos brazos y piernas están encadenados, y un grupo de serpientes que rodean a los personajes. El dios cautivo podría ser Dumuzi en el Inframundo (COLLON, 2005b, p. 178). 


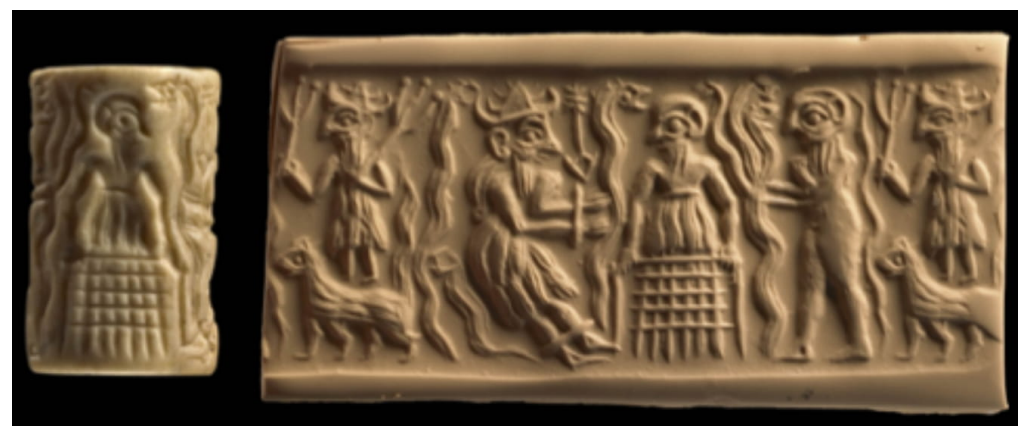

Fig. 9: BM 123279 / AN851933001

(C) The Trustees of the British Museum)

Por otra parte, un grupo de sellos paleo-acadios (e.g. MNB 1351 - fig. 10 - y BM 130693 - fig. 11) representa a un dios tirando de un árbol hacia abajo sobre una diosa que se arrodilla ante otra deidad masculina asomándose desde sus raíces. Al personaje, que sostiene el árbol, se lo identifica con Nergal. Por el contrario, Samuel Noah Kramer sugiere que el mismo sería Gilgameš, aunque también postula que "ninguna de las figuras se puede registrar con certeza" (1961 [1944], p. 32). Dominique Collon relaciona dicho motivo con los mitos de la naturaleza y el dios que muere y resucita (2005b, p. 178). Como el arquetipo del "dios doliente", la divinidad al pie del árbol sería Dumuzi y la figura femenina, que lo acompaña, Inanna.

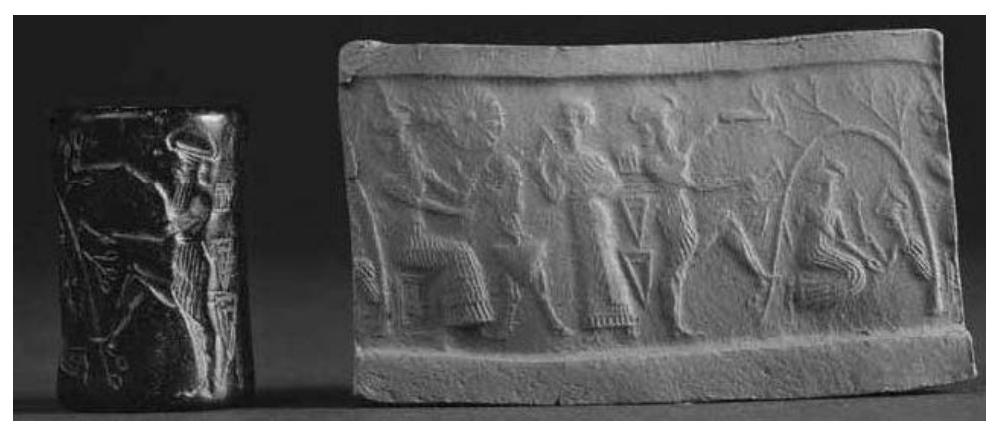

Fig. 10: El dios y el árbol (MNB 1351)

(C) R.M.N./F. Raux) 


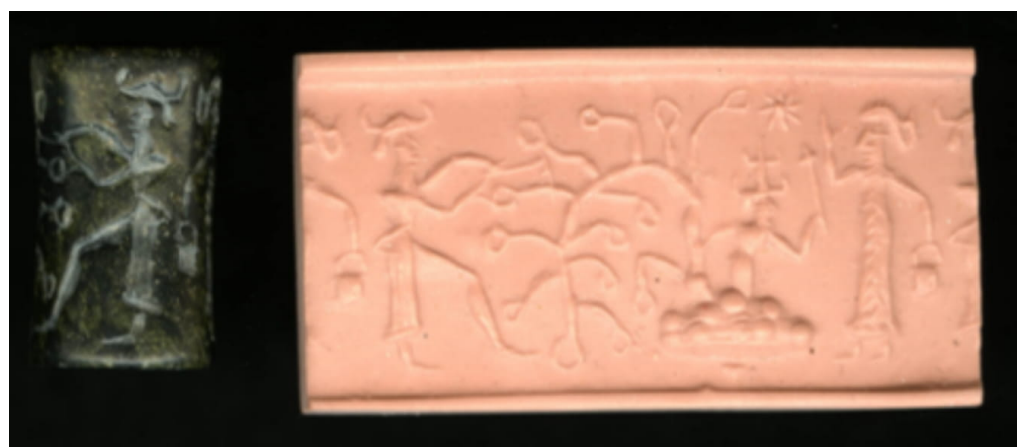

Fig. 11: El dios y el árbol (BM 130693 / AN1572525001)

(C) The Trustees of the British Museum)

Sin embargo, en la imaginería mesopotámica, hallamos una figura masculina que generalmente aparece de frente y desnuda a excepción de un cinturón de tres cadenas. El personaje es un ser barbado y su peinado consta de tres rizos a ambos lados del rostro, que Elizabeth Douglas Van Buren reconoce como Dumuzi-Abzu (1930, pls. LVI-LVII) y Wilfred Lambert lo vincula con el pastor Dumuzi (1979, p. 4). A la figura se la denomina simplemente como el "héroe" o "héroe desnudo" y, en la actualidad, se la conoce usualmente como lahmu, el "peludo" (VAN DIJK, 2011, pp. 67-68), y, en consecuencia, no podría equipararse con Dumuzi.

El modo adoptado para representar a Dumuzi consistía en una figura de un dios muerto en un sarcófago, y, por ello, se manifiesta como una deidad del averno. Este motivo se encuentra en diversas placas de terracota (e.g. AO 8823 [fig. 12] y AO 16944) y en sellos cilindros (AO 11566) (fig. 13) de época de Isin/Larsa y/o paleobabilónica respectivamente. En asiriología, no existe acuerdo sobre la identidad del dios representado: algunos sostienen que es Dumuzi (AMIET, 1980, p. 582), mientras que otros afirman que es Nergal (BLACK \& GREEN, 1992, p. 136).

No obstante, sabemos que ambas eran deidades del Inframundo: Nergal era considerado en diversas inscripciones esposo de Ereškigal y se lo evocaba como gobernante de la Tierra sin Retorno desde mediados del segundo milenio a.C., y todas las encarnaciones locales de jóvenes dioses dolientes fueron asimiladas con Dumuzi 
durante la época paleo-babilónica (KATZ, 2003, pp. 389 y 415). MarieThérèse Barrelet identifica a la figura de uno de estos dioses muertos (AO 16944) como un "dieux aux oreilles de taureau" (1968, p. 308). La inclusión de las orejas de toro puede ser pertinente porque Dumuzi se asoció siempre con el bóvido, mientras que no hallamos evidencia de Nergal vinculada con este animal ${ }^{15}$.

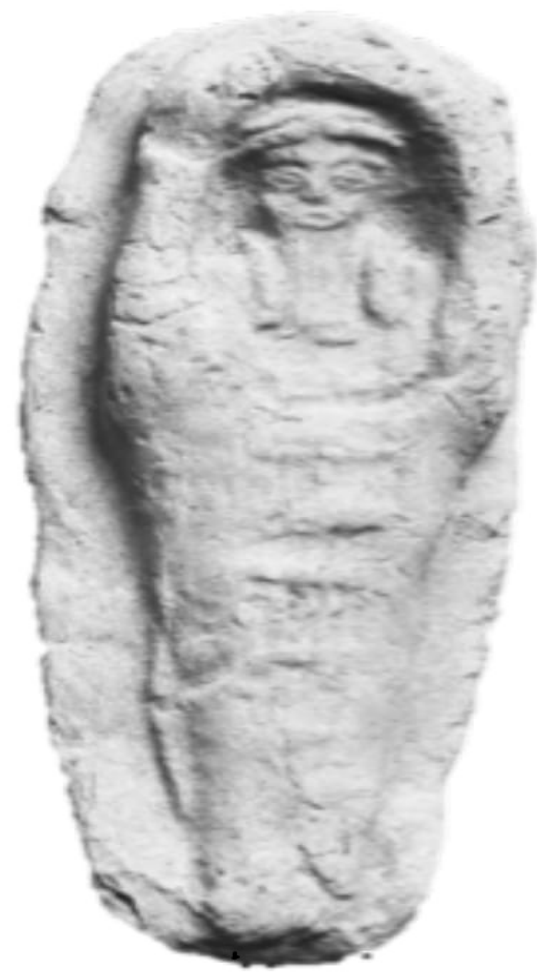

Fig. 12: Dios muerto en el sarcófago (AO 8823) (ㄷ) Musée du Louvre / Pierre et Maurice Chuzeville)

${ }^{15}$ Sin embargo, las orejas de toro parecen haber sido atributos muy comunes de los dioses representados de frente en las placas de terracota de los períodos de Isin/Larsa y paleo-babilónico. 


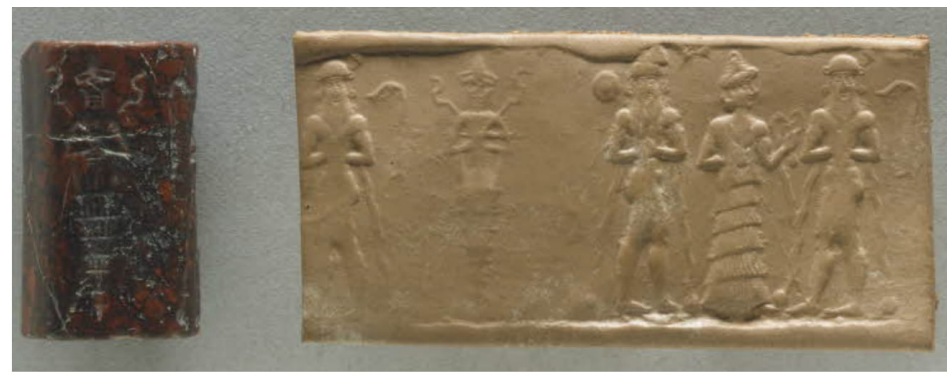

Fig. 13: Dumuzi como “dios muerto". Es el segundo personaje contando desde la izquierda (AO 11566)

(C) Musée du Louvre / Christian Larrieu)

En la iconografía del dios muerto en un sarcófago, se reconoce un arma en forma de hoz o un cetro en cada mano de dicho personaje. El símbolo de Nergal era un cetro con forma de león con una o dos cabezas, similar al manipulado por el dios en el sarcófago (BLACK \& GREEN, 1992, p. 136). El cetro del dios muerto, sin embargo, no posee ninguna cabeza de león; de manera tal que, la vara no puede considerarse un emblema de Nergal. De hecho, el cetro en forma de hoz "fue considerado como un símbolo de poder divino" (DOUGLAS VAN BUREN, 1930, p. 131) y, por lo tanto, puede ser portado por cualquier deidad.

Algunos autores, han sugerido que Nergal no es el nombre de una única divinidad, sino que más bien debe entenderse como un término genérico para cualquier deidad del Inframundo (LEICK, 1998, p. 127). De este modo, la cuestión de si la imagen del dios muerto en el sarcófago corresponde a Nergal o a Dumuzi aún es discutible.

\section{A modo de balance}

Como señalábamos al comienzo, el cuerpo humano en un sentido socio-histórico y, en simultáneo, cultural es un "cuerpo simbólico", esto es, "corporeidad" sometida al movimiento del devenir temporal y no restringida a una espacialidad geométrica establecida (cf. 
DUCH \& MÈLICH, 2012 [2005], p. 22). De este modo, la corporeidad no sólo refiere a la fisicalidad de la carne per se, sino también a las representaciones y usos simbólicos derivados de la misma, como queda demostrado a partir de la iconografía y las narraciones míticas, que no tienen por qué ser un espejo exacto del contexto, pero sí servir de canal de expresión de los imaginarios en los cuales se generan y reproducen.

En el caso que aquí analizamos, la dialéctica Inanna/Dumuzi es reconocible tanto en las representaciones iconográficas como en los textos literarios que hemos mencionado. Asimismo, si bien los mitos no son un retrato de la realidad, sino que más bien dan cuenta de un mundo hipertrofiado (de la misma forma que la imaginería visual conectada con lo sagrado), sí funcionan como un espejo del universo social en el que se expresa la praxis de quienes los compusieron/redactaron y reprodujeron (tanto en el contexto de las escuelas de escribas como a través de prácticas ceremoniales).

De esta manera, la corporeidad multívoca y liminal de Inanna se vinculaba en la antigua Mesopotamia y, por extensión, en diversos cultos del Mediterráneo oriental y de grupos etnográficos que actualmente continúan siendo estudiados, con una metáfora de terror y misterio, que adoptó un rostro femenino. El cuerpo de la mujer representaba en el plano religioso a la creación, i.e. la vida, pero también a la destrucción y la muerte: el útero encarnaba no sólo el habitáculo para acceder a la vida, sino también para transformarse en un difunto. Inanna personificaba en el DII y en otros mitos al cuerpo lleno de vida y a las potencias vinculadas con el orden y la permanencia (los me o "fuerzas divinas"), y, simultáneamente, la deidad simbolizaba la decrepitud, lo nefasto, irracional y dionisíaco. Así, la desnudez de la diosa equivale en el plano mítico a la aniquilación de las fuerzas que dinamizaban el cosmos, la neutralización de los atributos de poder y magnificencia de la deidad.

Por el contario, el cuerpo de Dumuzi - asimilado al arquetipo del "dios doliente" - se presentaba como una entidad endeble, víctima de su consorte. Asimismo, tanto en las representaciones plásticas como en las textuales, la corporeidad de Inanna y Dumuzi da cuenta de los modos utilizados en la construcción de sus respectivos cuerpos divinos, asimilados a metáforas multívocas de lo religioso, ya sea como algo fascinante o tremendo. En efecto, la liminalidad de Inanna a lo largo del $D I I$ - fascinante/tremenda/divina y abyecta/humana - se complementa 
con la imagen de su consorte Dumuzi, el cual aparece como el dios que debe ser sacrificado y, por ende, personifica la decrepitud que padecen hasta las divinidades. No es fortuito que los monarcas, en tanto novios sagrados de Inanna, se identificaran con Dumuzi y, en efecto, se exaltaba así la importancia que poseía el cuerpo real, pero en simultáneo se marcaba su mortalidad, aunque la institución monárquica fuera considerada la fuente de orden por antonomasia in illo tempore.

\section{Abreviaturas}

ATU FALKENSTEIN, Adam. Archaische Texte aus Uruk, bearbeitet und herausgegeben (Ausgrabungen der Deutschen Forschungsgemeinschaft in Uruk-Warka 2). Berlin/ Leipzig: Deutsche Forschungsgemeinschaft, Kommissionsverlag Otto Harrassowitz, 1936. CAD ROTH, Martha et alii (eds.). The Assyrian Dictionary of the Oriental Institute of the University of Chicago. Chicago: The Oriental Institute of the University of Chicago, 1956-2006. ePSD TINNEY, Stephen (ed.). Electronic Pennsylvania Sumerian Dictionary, 2004-. Disponible en: http://psd.museum.upenn.edu/epsd/ ETCSL BLACK, Jeremy et alii (eds.). The Electronic Text Corpus of Sumerian Literature. Oxford: Oriental Institute of the University of Oxford, 1998. Disponible en: http://etcsl.orinst.ox.ac.uk/ MEA LABAT, René \& Florence MALBRAN-LABAT. Manuel d'épigraphie akkadienne. Paris: Librairie Orientaliste PaulGeuthner, 2002 [1948].

\section{Bibliografía}

ALBENDA, Pauline. The "Queen of the Night" Plaque: A Revisit. Journal of the American Oriental Society, vol. 125, n. 2, 2005, p. 171190.

AMIET, Pierre. Art of the Ancient Near East. New York: Harry N. Abrams, Inc., 1980.

ARUZ, Joan, Kim BENZEL \& Jean M. EVANS (eds.). Beyond Babylong; Art, Trade, and Diplomacy in the Second Millennium BC. New York: Metropolitan Museum of Art, 2008. 
ASHER-GREVE, Julia M. Stepping into the Maelstrom: Women, Gender and Ancient Near Eastern Scholarship. NIN: Journal of Gender Studies in Antiquity, vol. 1, 2000, p. 1-22.

ASHER-GREVE, Julia M. The Essential Body: Mesopotamian Conceptions of the Gendered Body. Gender and History, vol. 9, n. 3, 1997, p. 432-461.

BAHRANI, Zainab. Women of Babylon: Gender and Representation in Mesopotamia. London: Routledge, 2001.

BARRELET, Marie-Thérèse. Figurines et Reliefs en Terre Cuite de la Mésopotamie Antique I: Potiers, termes de Métier, Procédés de Fabrication et Production. Paris: Librairie Orientaliste Paul Geuthner, 1968.

BLACK, Jeremy \& Anthony GREEN. Gods, Demons and Symbols of Ancient Mesopotamia. Austin: University of Texas Press, 1992.

BLACK, Jeremy et alii. The Electronic Text Corpus of Sumerian Literature. Oxford: Oriental Institute of the University of Oxford, 1998. BLACKING, John. The Anthropology of the Body. London: Academic Press, 1977.

BOULDING, Elise M. The Underside of History: A View of Women through Time. New York: Halsted, 1976.

CABRERA, Rodrigo. El descenso de Inanna al templo: la transubstanciación apolíneo-fascinante y dionisíaco-tremenda del cuerpo monárquico en la circulación ritual, Tesis de licenciatura inédita. Buenos Aires: Universidad de Buenos Aires, 2013.

CABRERA, Rodrigo. Transtextualidades en la literatura mesopotámica. Vínculos palimpsestuosos entre El descenso de Inanna al Inframundo y la himnología real neo-sumeria y paleo-babilónica. Revista Mundo Antigo. Revista científica eletrônica, ano 4, vol. 4, n. 7, 2015, p. 79-102. Disponible en: http://www.nehmaat.uff.br/revista/2015-1/artigo042015-1.pdf

COLLON, Dominique. British Museum Objects in Focus: The Queen of the Night. London: The British Museum Press, 2005a.

COLLON, Dominique. First Impressions: Cylinder Seals in the Ancient Near East. London: The British Museum Press, 2005b.

COUTO-FERREIRA, M. Erica \& Agnès GARCÍA-VENTURA. Engendering Purity and Impurity in Assyriological Studies: A Historiographical Overview. En: DE GROOT, Joanna \& Sue 
MORGAN (eds.). Sex, Gender and the Sacred: Reconfiguring Religion in Gender History. Malden: Wiley-Blackwell, 2014, p. 119-134.

COUTO-FERREIRA, M. Erica. Uterine Architectures: Womb and Space in Sumero-Akkadian Sources. En: COUTO-FERREIRA, M. Erica \& Lorenzo VERDERAME (eds.). Cultural Constructions of the Uterus in Pre-modern Societies, Past and Present. Newcastle upon Tyne: Cambridge Scholars Publishing, 2018, p. 34-54.

CSORDAS, Thomas. Embodiment and Cultural Phenomenology. En: WEISS, Gail \& Honi FERN HABER (eds.). Perspectives on Embodiment. New York: Routledge, 1999, p. 143-162.

CSORDAS, Thomas. Somatic Modes of Attention. Cultural Anthropology, vol. 8, n. 2, 1993, p. 135-156.

CSORDAS, Thomas. The Sacred Self: A Cultural Phenomenology of Charismatic Healing. Berkeley: The University of California Press, 1994.

DEMANGE, Françoise et alii. Louvre Visitor's Guide to Oriental Antiquities. Paris: Réunion des Musées Nationaux, 1995.

DOUGLAS VAN BUREN, Elizabeth. Clay Figurines of Babylonia and Assyria. Yale Oriental Series: Researches, vol. XVI. New York: AMS Press, 1930.

DOUGLAS VAN BUREN, Elizabeth. Symbols of the Gods in Mesopotamian Art. Roma: Pontificum Institutum Biblicum, 1945.

DUCH, Lluís \& MÈLICH, Joan-Carles. Escenarios de la corporeidad (Antropología de la vida cotidiana 2/1). Madrid: Trotta, 2012 [2005].

DURAND, Jean-Marie (ed.). La femme dans le Proche-Orient Antique: Compte Rendu de la XXXIII Rencontre Assyriologique Internationale, Paris, 7-10 juillet 1986. Paris: Éditions Recherche sur les Civilisations, 1987.

EMELIANOV, Vladimir V. On the Early History of melammu. En: KOGAN, Leonid et alii (eds.). Language in the Ancient Near East, Proceedings of the $53^{e}$ Rencontre Assyriologique Internationale, vol. 1, part 1. Winona Lake: Russian State University for the Humanities by Eisenbrauns, 2010, p. 1109-1120.

EMELIANOV, Vladimir V. The Ruler as Possessor of Power in Sumer. En: GRININ, Leonid E. et alii (eds.). The Early State, its Alternatives and Analogues. Volgograd: Uchitel Publishing House, 2004, p. 181195. 
EMELIANOV, Vladimir V. Шумерский календарный ритуал: категория ME u весенние праздники. Санкт-Петербург: Петербургское востоковедение, 2009.

FALKENSTEIN, Adam. Archaische Texte aus Uruk, bearbeitet und herausgegeben (Ausgrabungen der Deutschen Forschungsgemeinschaft in Uruk-Warka 2). Berlin/Leipzig: Deutsche Forschungsgemeinschaft, Kommissionsverlag Otto Harrassowitz, 1936.

FARBER-FLÜGGE, Gertrud. Der Mythos „Inanna und Enki“ unter besonderer Berücksichtigung der Liste der Me (Studia Pohl. Dissertationes scientificae de rebus orientis antique 10). Roma: Biblical Institute Press, 1973.

FOUCAULT, Michel. El nacimiento de la clínica. Madrid: Siglo XXI, 1993 [1963].

FOUCAULT, Michel. Historia de la sexualidad I. La voluntad de saber. Madrid: Siglo XXI, 1995 [1976].

FOUCAULT, Michel. Vigilar y castigar. Buenos Aires: Siglo XXI, 1987 [1975].

HANSEN, Donald. Art of the Royal Tombs of Ur: A Brief Interpretation. En: ZETTLER, Richard L. \& Lee HORNE (eds.). Treasures from the Royal Tombs of Ur. Philadelphia: University of Pennsylvania, 1998, p. 43-72.

HARRIS, Rivkah. Gender and Aging in Mesopotamia: The Gilgamesh Epic and Other Ancient Literature. Norman: University of Oklahoma Press, 2000.

HARRIS, Rivkah. Inanna-Ishtar as Paradox and a Coincidence of Opposites. History of Religions, vol. 30, n. 3, 1991, p. 261-278.

JACKSON, Michael. Introduction. Phenomenology, Radical Empiricism and Anthropological Critique. En: JACKSON, Michael (comp.). Things as They are. New Directions in Phenomenological Anthropology. Bloomington: Indiana University Press, 1996, p. 1-50.

JACKSON, Michael. Knowledge of the Body. Man, vol. 18, n. 2, 1983, p. 327-345.

JACKSON, Michael. Paths toward a Clearing: Radical Empiricism and Ethnographic Inquiry. Bloomington: Indiana University Press, 1989.

JACOBSEN, Thorkild. Pictures and Pictorial Language (The Burney Relief). En: MINDLIN, Murray, Markham J. GELLER \& John E. WANSBROUGH, (eds.). Figurative Language in the Ancient Near 
East. London: School of Oriental and African Studies, University of London, 1986, p. 1-11.

JACOBSEN, Thorkild. The Treasures of Darkness: A History of Mesopotamian Religion. New Haven: Yale University Press, 1976.

JUSTEL, Josué J. \& Agnès GARCÍA-VENTURA (eds.). Las mujeres en el Oriente cuneiforme. Alcalá de Henares: Servicio de Publicaciones de la Universidad de Alcalá, 2018.

JUSTEL, Josué J. Mujeres y género en la historiografía del Próximo Oriente Antiguo: pasado, presente y futuro de la investigación. Arenal. Revista de Historia de las Mujeres, vol. 18, n. 2, 2011, p. 371-407.

KATZ, Dina. How Dumuzi Became Inanna's Victim: On the Formulation of "Inanna's Descent". Acta Sumeriologica, n. 18, 1996, p. 93-103.

KATZ, Dina. Inanna's Descent and Undressing the Dead as a Divine Law. Zeitschrift für Assyriologie und Vorderasiatische Archäologie, vol. 85, n. 2, 1995, p. 221-233.

KATZ, Dina. The Image of the Netherworld in the Sumerian Sources. Bethesda: CDL Press, 2003.

KING, Leonard William. Cuneiform Texts from Babylonian Tablets in the British Museum, part XV. London: The Trustees of the British Museum, 1902.

KRAELING, Emil Gottlieb. A Unique Babylonian Relief. Bulletin of the American Schools of Oriental Research, n. 67, 1937, p. 16-18.

KRAMER, Samuel Noah. Additional Material to "Inanna's Descent to the Nether World". Revue d'Assyriologie et d'Archéologie Orientale, n. 36, 1939, p. 68-80.

KRAMER, Samuel Noah. Dumuzi's Annual Resurrection: An Important Correction to "Inanna's Descent". Bulletin of the American Schools of Oriental Research, n. 183, 1966, p. 31.

KRAMER, Samuel Noah. Inanna's Descent to the Nether World. Revue d'Assyriologie et d'Archéologie Orientale, n. 34, 1937, p. 93-134.

KRAMER, Samuel Noah. Inanna's Descent to the Nether World: Continued and Revised. Journal of Cuneiform Studies, vol. 4, n. 4, 1950a, p. 199-214.

KRAMER, Samuel Noah. Inanna's Descent to the Nether World: Continued. Proceedings of the American Philosophical Society, vol. 94, n. 4, 1950b, p. 361-363. 
KRAMER, Samuel Noah. Inanna's Descent to the Nether World: Continued and Revised. Second Part: Revised Edition of "Inanna's Descent to the Nether World". Journal of Cuneiform Studies, vol. 5, n. 1, 1951, p. 1-17.

KRAMER, Samuel Noah. Ishtar in the Nether World according to a New Sumerian Text. Bulletin of the American Schools of Oriental Research, n. 79, 1940, p. 18-27.

KRAMER, Samuel Noah. Sumerian Literature: A preliminary Survey of the Oldest Literature in the World. Proceedings of the American Philosophical Society, vol. 85, n. 3, 1942, p. 293-323.

KRAMER, Samuel Noah. Sumerian Mythology: A Study of Spiritual and Literary Achievement in the Third Millennium BC. New York: Harper \& Brothers, 1961 [1944].

LABAT, René \& Florence MALBRAN-LABAT. Manuel d'épigraphie akkadienne. Paris: Librairie Orientaliste PaulGeuthner, 2002 [1948].

LAMBERT, Wilfred George. Near Eastern Seals in the Gulbenkian Museum of Oriental Art, University of Durham. Iraq, vol. 41, n. 1, 1979, p. 1-45.

LANGDON, Stephen. Historical and Religious Texts from the Temple Library of Nippur (Cuneiform Texts from the British Museum 31). München: The Babylonian Expedition of the University of Pennsylvania Series A, 1914.

LEICK, Gwendolyn. A Dictionary of Near Eastern Mythology. London: Routledge, 1998.

LERNER, Gerda. The Creation of Patriarchy (Women and History 1). New York/Oxford: Oxford University Press, 1986.

LESKO, Barbara S. (ed.). Women's Earliest Records from Ancient Egypt and Western Asia. Proceedings of the Conference on Women in the Ancient Near East, Brown University, Providence, Rhode Island November 5-7, 1987 (Brown Judaic Studies 166). Atlanta: Scholars Press, 1989.

MARCHESI, Gianni \& Nicolò MARCHETTI. Royal Statuary in Early Dynastic Mesopotamia. Winona Lake: Eisenbrauns, 2011.

MAUSS, Marcel. Sociología y antropología. Madrid: Tecnos, 1971 [1936].

NIETZSCHE, Friedrich. Asi habló Zaratustra. Un libro para todos y para ninguno. Buenos Aires/Madrid: Alianza, 1992 [1883-1885]. 
NIETZSCHE, Friedrich. El anticristo. Maldición sobre el cristianismo. Buenos Aires/Madrid: Alianza, 1996 [1888].

NIETZSCHE, Friedrich. El nacimiento de la tragedia o Grecia y el pesimismo. Buenos Aires/Madrid: Alianza, 1990 [1871-1872].

NISSEN, Hans J. The Archaic Texts from Uruk. World Archaeology, vol. 17, n. 3, 1986, p. 317-334.

OBERHUBER, Karl. Der numinose Begriff ME im Sumerischen (Innsbrucker Beiträge zur Kulturwissenschaft 17). Innsbruck: Sprachwiss. Inst. der Univ, 1963.

OCHSHORN, Judith. The Female Experience and the Nature of the Divine. Bloomington: Indiana University Press, 1981.

POEBEL, Arno. Historical and Grammatical Texts (Publications of the Babylonian Section V). Philadelphia: Museum of the University of Pennsylvania, 1914.

ROHRLICH-LEAVITT, Ruby. State Formation in Sumer and the Subjugation of Women. Feminist Studies, vol. 6, n. 1, 1980, p. 76-102. ROHRLICH-LEAVITT, Ruby. Women in Transition: Crete and Sumer. En: BRIDENTHAL, Renate \& Claudia KOONZ (eds.). Becoming Visible: Women in European History. Boston: Houghton Mifflin, 1977, p. 36-59.

ROSENGARTEN, Yvonne (con la colaboración de André BAER). Sumer et le sacré. Le jeu des Prescriptions (me), des dieux et des destins. Paris: Editions de Boccard, 1977.

ROTH, Martha et alii (eds.). The Assyrian Dictionary of the Oriental Institute of the University of Chicago. Chicago: The Oriental Institute of the University of Chicago, 1956-2006.

SCHMANDT-BESSERAT, Denise. When Writing Met Art; From Symbol to Story. Austin: University of Texas Press, 2007.

SLADEK, William R. Inanna's Descent to the Netherworld. Ann Arbor: University Microfilms, 1974.

SLOBODZIANEK, Iwo. Fureur, complainte et terreur d'Inanna: dynamiques de l'émotion dans les représentations religieuses littéraires sumériennes. Mythos, n. 4, 2010, p. 27-39.

SVÄRD, Saana \& Agnès GARCÍA-VENTURA (eds.). Studying Gender in the Ancient Near East. University Park: Eisenbrauns/The Pennsylvania State University Press, 2018.

SVÄRD, Saana. Power and Women in the Neo-Assyrian Palaces, Tesis de doctorado inédita. Helsinki: University of Helsinki, 2012a. 
SVÄRD, Saana. Women, Power and Heterarchy in the Neo-Assyrian Palaces. En: WILHELM, Gernot (ed.). Organization, Representation, and Symbols of Power in the Ancient Near East: Proceedings of the $54^{\text {th }}$ Rencontre Assyriologique Internationale at Würzburg 20-25 July 2008. Winona Lake: Eisenbrauns, 2012b, p. 507-518.

TEPPO, Saana. Agency and the Neo-Assyrian Women of the Palace. Studia Orientalia, vol. 101, 2007, p. 381-420.

VAN DIJK, Renate Marian. The Motif of the Bull in the Ancient Near East: An Iconographic Study, Tesis de maestría inédita. South Africa: University of South Africa, 2011.

VERDERAME, Lorenzo. La vestizione di Inanna. En: BOTTA, Sergio (ed.). Abiti, corpi, identità. Significati e valenze profonde del vestire. Firenze: Società Editrice Fiorentina, 2009, p. 63-73.

WILCKE, Claus. Inanna/Ištar. Reallexikon der Assyriologie und Vorderasiatischen Archäologie, vol. 5, 1976-1980, p. 74-87.

WINTER, Irene. Sex, Rhetoric, and the Public Monument: The Alluring Body of Naram-Sîn of Agade. En: BOYMEL KAMPEN, Natalie \& Bettina Ann BERGMANN (eds.). Sexuality in Ancient Art (Cambridge Studies in New Art History and Criticism). Cambridge/New York: Cambridge University Press, 1996, p. 11-26.

WINTER, Irene. Women in Public: The Disk of Enheduanna, the Beginning of the Office of EN-Priestess, and the Weight of Visual Evidence. En: DURAND, Jean-Marie (ed.). La femme dans le ProcheOrient Antique: Compte Rendu de la XXXIII ${ }^{e}$ Rencontre Assyriologique Internationale, Paris, 7-10 juillet 1986. Paris: Éditions Recherche sur les Civilisations, 1987, p. 189-201.

WOLKENSTEIN, Diane \& Samuel Noah KRAMER. Inanna, Queen of Heaven and Earth: Her Stories and Hymns from Sumer. New York: Harper \& Row Publishers, 1983.

ZGOLL, Annette. Der Rechtsfall der En-hedu-Ana im Lied Nin-mesarra. Münster: Ugarit-Verlag, 1997. 
